\title{
Protection by Cepharanthie of the Mitochondrial Function from Damage Induced by Snake Venom, Phospholipase $A_{2}$, Lysolecithin and Lead
}

\author{
Masanobu Miyahara, Kaname Aono*, Jorge Sancho Queseda*, Kunio \\ Shimono, Yuji Baba and Syoichi Yamashita \\ Department of Pathology and Department of Radiology*, Okayama University \\ Medical School, Okayama 700, Japan
}

\begin{abstract}
The action of cepharanthie, a biscoclaurine alkaloid, on disturbances of the mitochondrial function caused by snake venom, phospholipase $\mathrm{A}_{2}$, lysolecithin, lead and high temperature was examined. The alkaloid protected mitochondria from damage caused by these treatments. The results suggest that the alkaloid protects biomembranes from various damage with no effect of its own at a low concentration.
\end{abstract}

A previous paper reported that cepharanthie, a potent antihemolytic agent, protects red cell membranes from damage induced by snake venom, lysolecithin and lead acetate (8). The paper demonstrated that antihemolytic activity is due to its stabilizing action on the red cell membrane. The alkaloid also inhibits some membrane functions in the plasma membranes, e.g. histamine release from mast cells, and concanavalin A induced-cap formation in Ehrlich ascites tumor cells and monocytes(9). The molecular mechanism of the alkaloid on these membranes, however, is not clear. The present report focuses on whether similar membrane stabilizing actions occur in mitochondrial membranes whose molecular organization (2) differs from the above membranes. In this paper it is demonstrated that rat liver mitochondria treated with snake venom, phospholipase $\mathrm{A}_{2}$, lysolecithin, lead acetate or a high temperature show altered functions, and that the alkaloid protects them from disturbances caused by these treatments.

Mitochondria were isolated from livers of Wister strain rats weighing 250 to $300 \mathrm{~g}$ using the method of Hogeboom and Schneider (4), then they were suspended in icecold $0.25 \mathrm{M}$ sucrose- $10 \mathrm{mM}$ Tris. $\mathrm{HCl}, \mathrm{pH} 7.4$ at a concentration of $50 \mathrm{mg}$ protein per $\mathrm{ml}$. Respiration and oxidative phosphorylation were measured with a Clark oxygen electrode at $25^{\circ} \mathrm{C}$ as described previously (5). Potassium release from the mitochondria was measured and recorded with a potassium electrode (Electronic Instrument Ltd., Richmond, Surry, England, Model GKY 33B) connected to a pH meter (Toa Electronic Instrument Ltd., Tokyo, Japan, Model HM-20B) as described previously (6). ADP, phospholipase $A_{2}$ (from Naja naja), hen egg lysolecithin were purchased from Sigma Chem. Company, St. Louis, Miss., U.S.A.. Cepharanthie and snake venom (from Naja naja) were the generous gifts of Kaken Drug company, Tokyo, Japan. Other chemicals were commercial products of analytical grade. Snake venom was diluted to the appropriate concentration with $100 \mathrm{mM} \mathrm{K-PBS,} \mathrm{pH} \mathrm{7.4.} \mathrm{Cepharanthie}$ was dissolved in absolute ethanol. 


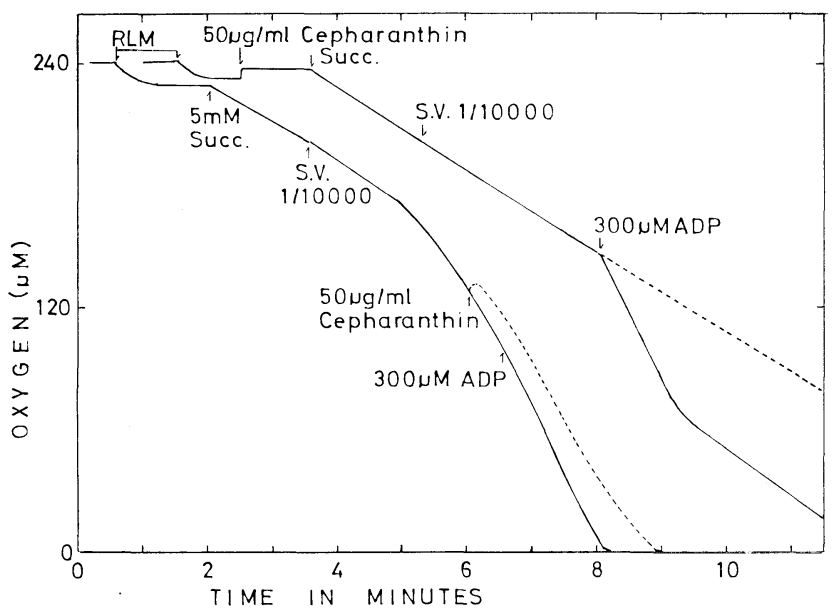

Fig. 1. Cepharanthie protectioe of rat liver mitochondria from snake venom-induced uncoupling. Mitochondria(6 mg protein) were suspended in $0.25 \mathrm{M}$ sucrose- $10 \mathrm{mM}$ Tris. $\mathrm{HCl}, \mathrm{pH} 7.4$ at $25^{\circ} \mathrm{C}$. Oxygen consumption was recorded as described in the text. The total volume of the reaction mixture was $3 \mathrm{ml}$. The order of the additions and the concentrations of agents are shown in the figure.

When mitochondria were suspended in $0.25 \mathrm{M}$ sucrose-10 mM Tris. $\mathrm{HCl}, \mathrm{pH}$ 7.4, an addition of a small amount of diluted snake venom stimulated the rate of succinate oxidation with a marked depression in oxidative phosphorylation. Fig. 1 shows that the stimulated rate increased with time and that an another addition of cepharanthie did not suppress the increased rate. When mitochondria were pretreated with cepharanthin $(16.6 \mu \mathrm{g} / \mathrm{mg}$ prot) there was no uncoupling of respiration, and oxidative phosphorylation remained less impaired with an ADP/0 ratio of 1.85 and the respiratory control, 2.97. Data indicate that the damaging action of snake venom is prevented by pretreating the mitochondria with the alkaloid. Similar metabolic damage was observed in mitochondria treated with phospholipase $A_{2}(0.35 \mu \mathrm{g} / \mathrm{mg}$ prot), and with lysolecithin $(20 \mu \mathrm{g} / \mathrm{mg}$ prot $)$ : the alkaloid protected the mitochondria from damage caused by these compounds (data not shown).

Lead acetate is known to induce potassium release from mitochondria, and this causes disturbances in mitochondrial respiration and oxidative phosphorylation $(6,7)$. When mitochondria were suspended in isotonic choline chloride- $10 \mathrm{mM}$ Tris. $\mathrm{HCl}, \mathrm{pH} 7.4$ at $30^{\circ} \mathrm{C}$, potassium was released from the mitochondria into the suspending media, a low concentration of lead acetate stimulating ion release (Fig. 2, a). But, if the mitochondria were pretreated with cepharanthie $(5 \mu \mathrm{g} / \mathrm{mg}$ prot $)$, ion release was depressed markedly. Temperature-dependent potassium release was also suppressed with an equal concentration of the alkaloid (Fig. 2b).

Fig. 3 shows the disturbance effects of lead acetate on mitochondrial respiration and oxidative phosphorylation. The results shown in Fig. 2 and those of a previous report (6) indicate that these disturbances caused by lead are depressed by pretreating mitochondria with cepharanthie $(8 \mu \mathrm{g} / \mathrm{mg}$ prot). Details of the protective effects of the alkaloid are summarized in Fig. 4. Mitochondria in the presence or absence of cepharanthie $(8 \mu \mathrm{g} / \mathrm{mg}$ prot) were treated as shown in Fig. 3. An increase in the concentration of added-lead resulted in a gradual decrease in respiratory control accompanied 


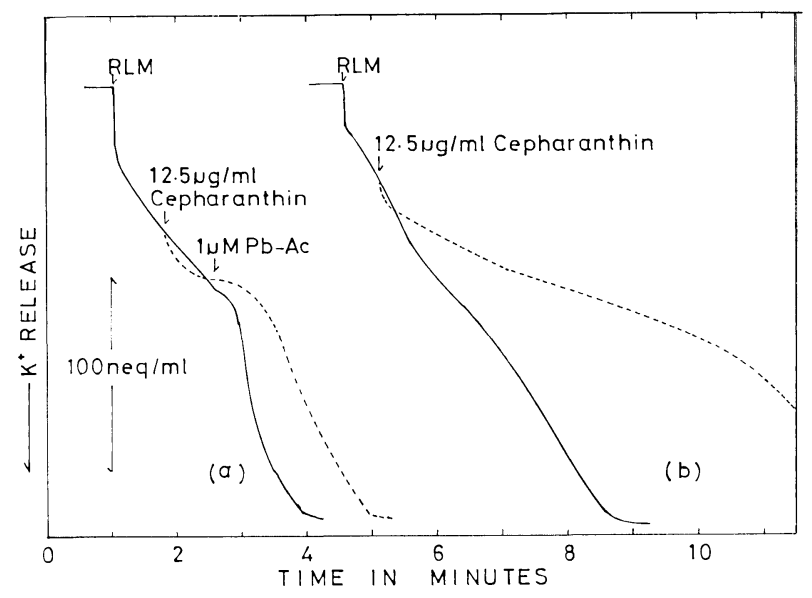

Fig. 2. Cepharanthie protection of mitochondria from temperature- and lead-dependent potassium release. Mitochondria (10 mg protein) were suspended in $4 \mathrm{ml}$ of $0.15 \mathrm{M}$ cholinechloride$10 \mathrm{mM}$ Tris. $\mathrm{HCl}, \mathrm{pH}$ 7.4. Potassium release from the mitochondria was recorded at $30^{\circ} \mathrm{C}$ as described in the text. The order of the additions and the concentrations of agents are shown in the figure.

by an increased rate in state 4 respiration, and $12.5 \mu \mathrm{M}$ lead completely uncoupled the respiration. However, if cepharanthie was present before the lead treatment, then the disturbance effects of lead at concentrations less than $10 \mu \mathrm{M}$ were depressed markedly, with no changes in the respiratory functions and in oxidative phosphorylation. Lead at a high concentration $(12.5 \mu \mathrm{M})$ produced considerable damage to the mitochondrial functions even in the presence of cepharanthin. The alkaloid, however, did not protect the mitochondrial functions from dinitrophenol-induced damage. Cepharanthie used at the present concentrations caused no changes in the mitochondrial functions.

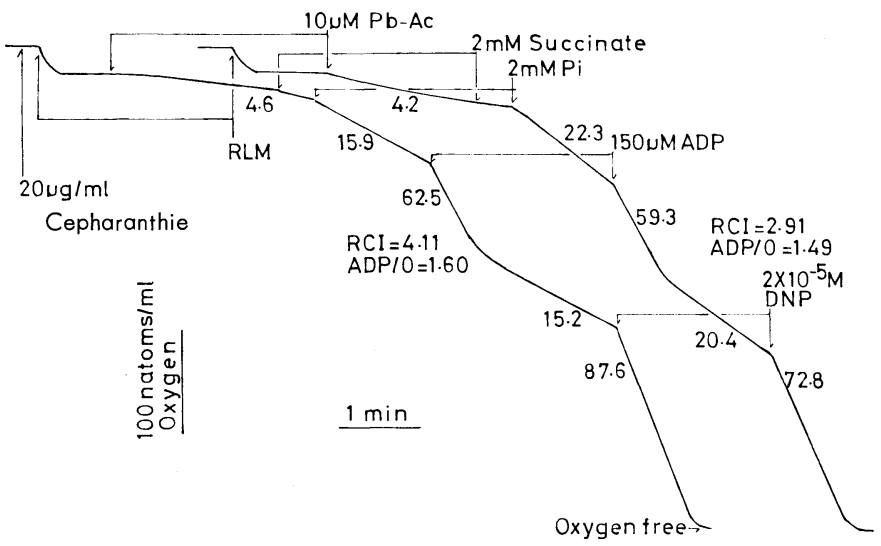

Fig. 3. Cepharanthie protection of mitochondrial functions from damage induced by lead. Mitochondria( $7.5 \mathrm{mg}$ protein) were suspended in $3 \mathrm{ml}$ of $0.1 \mathrm{M}$ sucrose containing $20 \mathrm{mM} \mathrm{KCl}$ and $5 \mathrm{mM}$ Tris. $\mathrm{HCl}, \mathrm{pH} 7.4$ at $25^{\circ} \mathrm{C}$. Oxygen consumption was recorded as described in the text. The order of the additions and the concentrations of agents are shown in the figure. Numbers on the curves indicate the rate of respiration ( $\mathrm{n}$ atoms oxygen $/ \mathrm{min} / \mathrm{mg}$ prot). 


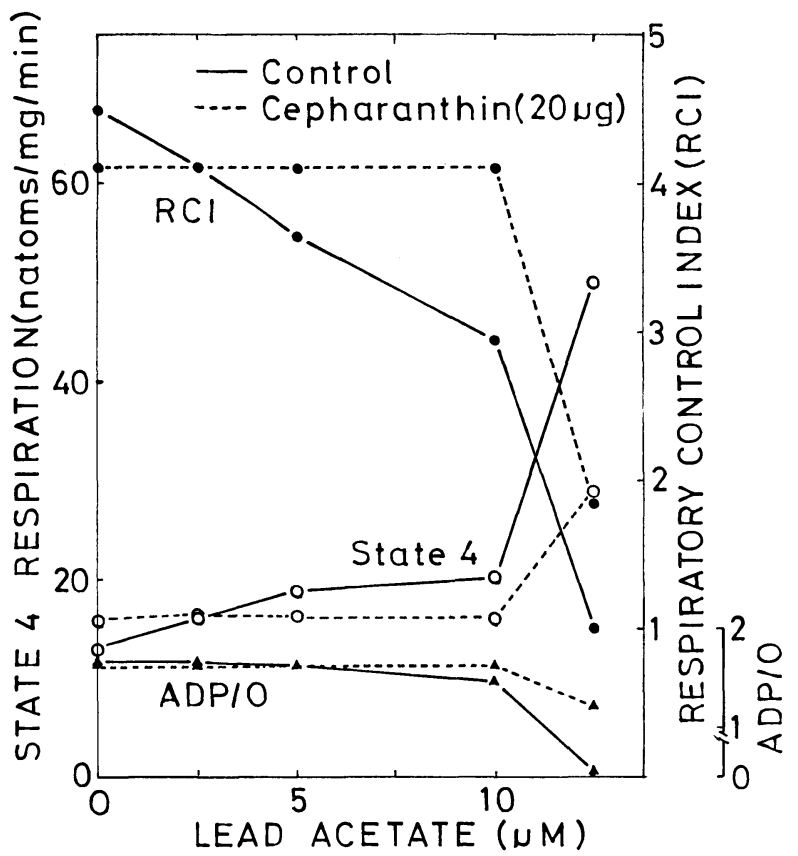

Fig. 4. The potent protective action of cepharanthie on lead-induced disturbances of mitochondrial functions. Experimental conditions were the same as those given in Fig. 3.

The study shows that cepharanthie, a biscoclaurin alkaloid, protects mitochondria from damage induced by snake venom, phospholipase $A_{2}$, lysolecithie, lead acetate and high temperature treatment. Similar protective actions of the alkaloid have been observed in red blood cells (8). These results emphasize that cepharanthin plays a role in the stabilization of membranes with different molecular organization. As reported here and in a previous paper (6), lead acts on mitochondria to release intramitochondrial potassium. This potassium release causes disturbances in respiration and oxidative phosphorylation. Snake venom, phospholipase $A_{2}$ and lysolecithin probably act on mitochondria in a different manner, one which dissociates the molecular organization of phospholipid molecules which make up the membrane structure $(1,3)$. The alkaloid produces similar protective actions with mitochondria and red blood cells to damage induced by these different-acting agents.

\section{REFERENCES}

1. Burstein, A., A. Loyter and E. Racker. Effect of phospholipases on the structure and function of mitochondria. J. Biol. Chem. 246, 4075-4082, 1971

2. Colbeau, A., J. Nachbaur and P.M. Vignais. Enzymic characterization and lipid composition of rat liver subcellular membranes. Biochim. Biophys. Acta 249, 462-492, 1971

3. Helenius, A. and K. Simons. Solubilization of membranes by detergents. Biochim. Biophys. Acta 415, 29-79, 1975

4. Hogeboom, G.H. Fractionation of cell components from animal tissues. In Methods in Enzymology, Vol. 1, ed. Colowick, S.P. and N.O. Kaplan, Academic Press, New York, pp 1619,1955 
5. Miyahara, M. Inhibition of mitochondrial energy transfer reactions by 5,5'-dithiobis(2-nitrobenzoic acid), Ellman's reagent. Arch. Biochem. Biophys. 134, 590-596, 1969

6. Miyahara, M. and K. Utsumi. Oxidative phosphorylation controlled by potassium in rat liver mitochondria. Cell Struct. Funct. 1, 51-59, 1975

7. Scott, K.M., K.M. Hwang, M., Jurkwitz and G.P. Brierley. Ion transport by heart mitochondria. XXIII. The effects of lead on mitochondrial reactions. Arch. Biochem. Biophys. 147, 557-567, 1971

8. Utsumi, K., M. Miyahara, M. Inoue, M. Mori, K. Sugiyama and J. Sasaki. Inhibition by cepharanthie of red blood cell potassium release induced by lead acetate and lysolecithin. Cell Struct. Funct. 1, 133-136, 1975

9. Utsumi, K., M. Miyahara, K. Sugiyama and J. Sasaki. Effect of the biscoclaurin alkaloid on the cell membrane as related to membrane fluidity. Acta Histochem. Cytochem. 9, 59-68, 1976

(Received for publication, January 12, 1978) 